University of Nebraska - Lincoln

DigitalCommons@University of Nebraska - Lincoln

November 2006

\title{
Working memory, executive functioning, and children's mathematics
}

R. Bull

K. A. Espy

University of Nebraska-Lincoln, kespy2@unl.edu

Follow this and additional works at: https://digitalcommons.unl.edu/dcnlfacpub

Part of the Neurosciences Commons

Bull, R. and Espy, K. A., "Working memory, executive functioning, and children's mathematics" (2006). Developmental Cognitive Neuroscience Laboratory - Faculty and Staff Publications. 30.

https://digitalcommons.unl.edu/dcnlfacpub/30

This Article is brought to you for free and open access by the Developmental Cognitive Neuroscience Laboratory at DigitalCommons@University of Nebraska - Lincoln. It has been accepted for inclusion in Developmental Cognitive Neuroscience Laboratory - Faculty and Staff Publications by an authorized administrator of DigitalCommons@University of Nebraska - Lincoln. 


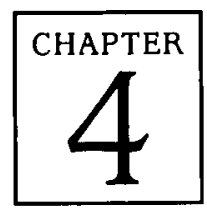

\title{
Working Memory, Executive Functioning, and Children's Mathematics
}

\author{
REBECCA BULL \\ University of Aberdeen \\ KIMBERLY ANDREWS ESPY \\ University of Nebraska-Lincoln
}

Approximately $3-6 \%$ of school-age children are estimated to have mathematics difficulties (Badian, 1983; Gross-Tsur, Manor, \& Shalev, 1996; Kosc, 1974, Lewis, Hitch, \& Walker, 1994). There are many more children in regular school classrooms who struggle with mathematics but whose performance is not considered sufficiently poor to be classified as meriting a specific disability in mathematics. Specific mathematic learning disability $(M L D)$ is defined in psychiatric and educational venues as a large discrepancy between mathematics ability compared to reading and general intellectual ability, although the size of the discrepancy required varies. To further complicate matters, mathematic difficulties are associated with other developmental disorders, in particular nonverbal learning disabilities (Rourke, 1993; Rourke \& Conway, 1997). It is surprising that the cognitive underpinnings of mathematic abilities have not been well described in typically developing children, those with neurodevelopmental disorders, or those with MLD. The purpose of this chapter is to examine the role of working memory (WM) and the central executive (CE), originally described by the Baddeley and Hitch (1974) model, in children's mathematic competence.

Mathematics is a complex domain, and a whole host of cognitive skills contribute to performance. In young children, mathematics competence is 
described by proficient counting, whereas in a college student, mathematics competence is marked by solving complex trigonometric problems and integrating equations. Not surprisingly, different cognitive abilities likely contribute to mathematics performance across development. Because of the greater complexity of algebra and geometry, developmental models are lacking. In contrast, more progress has been made in understanding the development of children's basic arithmetic skills (see in particular the work of Siegler, 1988; Siegler \& Shrager, 1984). As such, many studies choose to focus on the procedural difficulties and related cognitive limitations shown by children when solving basic arithmetic problems. Several investigators have suggested that basic arithmetic and number skills form the building blocks for acquisition of more complex mathematic skills (e.g., Geary \& Burlingham-Dubree, 1989) based on the strong relationship of arithmetic accuracy and response times to general mathematic proficiency. Therefore, evidence across the developmental age range will be presented to identify age-related communalities and differences.

One issue that complicates the study of the cognitive underpinnings of mathematics proficiency is how mathematic abilities are assessed. Regardless of whether preschool, school-age, or adolescent students are studied, mathematic proficiencies can be measured by traditional, individually administered standardized achievement tests-for example, mathematic subtests from the Wide Range Achievement Test (WRAT-R; Woodcock \& Johnson, 1989) and the Wechsler Intelligence Scales (WPPSI; Wechsler, 1990; WISC, Wechsler, 1977), individually administered problem-based assessments (Test of Everyday Mathematics Ability, TEMA), or group-administered curriculum assessments carried out by schools (e.g., California, lowa Math, curriculum key stage assessments, and Performance Indicators in Primary School). There may be important differences in the identified cognitive substrates dependent on the measurement method. Therefore, diverse evidence relating WM and various mathematic skills, measured by different methods, are presented here.

\section{WORKING MEMORY MODEL}

Cognitive studies of mathematic achievement and disorder provide a valuable insight into the deficits that might underlie difficulties in learning mathematics. Many of these studies have used the WM model of Baddeley and Hitch (1974, see also Baddeley, 1986, 1996, 2000 for recent developments of the WM model) as a framework within which to study a range of cognitive skills. Although there are many models of WM, executive control, or both (Miyake \& Shah, 1999), most researchers now agree that the process of mental arithmetic calculation involves WM to a substantial degree. Baddeley and Hitch (1974) proposed a multi-modal model with WM consisting of three subcomponents: the central executive (CE), the phonologi- cal loop (PL), and the visuo-spatial sketchpad (VSSP). The two "slave" systems, the PL and the VSSP, are specialized for processing language-based and visuo-spatial information, respectively. The $\mathrm{CE}$ is responsible for controlling the two slave systems, allocating attentional resources between them, and mediating the relation between WM short-term storage and retrieval from long-term memory (LTM; Baddeley, 1999).

Baddeley suggests that the PL itself can be divided into two separate subcomponents: a passive phonological store and an active phonological rehearsal mechanism. Information held in the phonological store is subject to decay, unless it can be refreshed by subvocal rehearsal, a process akin to repeating under one's breath the information one is trying to retain. Subvocal rehearsal, then, can be disrupted by secondary tasks that also use the verbal resources of the PL. This characteristic of the PL has been used ingeniously by several researchers to study PL processes, using the secondary or dual-task methodology. For example, the use of articulatory suppression (repeating a word such as "the") as an active phonological secondary task disrupts performance of a primary verbal task, such as digit recall.

The second slave system of WM, the VSSP, is less well specified. Until recently the VSSP has been treated as a single component, responsible for the processing of visual and spatial information. Logie and his associates (e.g., Logie, 1986, 1995; Logie \& Marchetti, 1991; Pearson, 2001) have been instrumental in deepening our understanding of the nature of the VSSP. The VSSP also has been studied by examining selective interference through dual-task methods. Quinn and McConnell $(1999,2000)$ have demonstrated that secondary visual tasks (e.g., dynamic visual noise) interfere more with performance on the primary visual task than do secondary spatial tasks The converse also is true-that is, secondary spatial tasks (e.g., spatial tapping) have a greater negative effect on performance on the primary spatial task than do secondary visual tasks (Logie, 1995; Meiser \& Klauer 1999). However, the attentional/executive demands of visuo-spatial WM tasks are still the matter of much debate (Hamilton, Coates, \& Heffernan, 2003).

The CE, despite being arguably the most important of the three components of WM, is certainly the least well defined. Although most researchers consider the $\mathrm{CE}$ to be multi-functional and complex, there remains considerable debate, both about the precise nature of its functions and whether there is indeed unity or diversity of the functions. The CE is thought to be of limited capacity, but it controls the allocation of resources between the PL and the VSSP. Miyake, Friedman, Rettinger, Shah, and Hegarty (2001) suggest that the VSSP has a much closer relationship with the CE than the PL, claiming that the VSSP can place much heavier demands on the CE. In view of this dubiety, it has been difficult to ascertain the most appropriate tasks for measuring its supposed functions. Most experimental tasks attempt to obtain a measure of the participants' abilities to combine con current processing and storage by using such measures as listening span 
(Daneman \& Carpenter, 1980) or counting span (Case, Kurland, \& Goldberg, 1982).

This chapter begins with a brief discussion of research examining the slave systems of WM and their role in children's arithmetic, followed by a more detailed examination of the recent research investigating the potential role of the functions subserved by the $C E$.

\section{ARITHMETIC AND THE SLAVE SYSTEMS}

Hunter (1957) saw mental calculation as "a succession of stages," each part of a calculation being carried out and stored until the next part of the calculation is completed before processing the products of the two stages. Hitch (1978) suggested that the performance of mental arithmetic required some form of "working storage" but did not speculate about its precise nature at that point. More recent studies with adults, however, have found strong evidence of a major role for the language-based PL in exact arithmetic calculation. Logie, Gilhooly, and Wynn (1994) asked participants to add two-digit numbers while simultaneously performing other tasks known to selectively disrupt the three components of WM. This dual-task technique is used to demonstrate how, when a task is of a certain nature (e.g., phonological, visuo-spatial, or executive), the posited limited resources of the component of WM involved can be engaged. If the loading is sufficient, and if the task being performed is dependent on that aspect of WM, performance of the primary task, secondary task, or both will be disrupted. Logie et al. used articulatory suppression as an active phonological secondary task. Loading the PL in this way prevents subvocal rehearsal and, consequently, information in the phonological store will be subject to decay. They found that performance of the concurrent secondary verbal task had a significant effect on arithmetic performance. Performance of the secondary task was also disrupted by a concurrent arithmetic task. Using a different methodology, where the phonological similarity of the digits is manipulated, Noel, Desert, Aubrun, and Seron (2001) found that adults' performance on arithmetic problems deteriorated significantly where the digits used were phonologically similar, suggesting that PL resources are used in the temporary storage of addends. Similarly, Hecht (2002) observed that where adults have to rely on counting strategies for solving even simple arithmetic problems, phonological and $C E$ resources are necessary for the efficient execution of that strategy. Therefore, from studies of aduits' arithmetic performance, there is robust evidence that the PL plays a critically important role, potentially because of the need to hold the operands in some form of short-term storage

Studies investigating the role of the VSSP in adult arithmetic are much less common. Heathcote (1994), in a study of adult arithmetic performance, found that multi-digit addends are simultaneously stored in both phonolog- ical and visual-spatial memory, evidenced by the disruption of calculation performance by a secondary visuo-spatial task, particularly on complex addition problems requiring carrying. Heathcote concluded that, whereas the PL holds the initial problem and running totals, the VSSP is a "mental blackboard or workbench" (p. 237), responsible for the spatial aspects of the problem such as number place and carrying. Hayes (1973) described visual imagery as an alternative to the external cues usually generated by paper and pencil. Others also have suggested that the use of mental number lines and spatial arrangements can support mental calculation (e.g. Dehaene, 1992; Seron, Pesenti, Noel, Deloche, \& Cornet, 1992) and that visual-spatial skills are particularly important in certain types of mathematics problems, such as geometry (Hartje, 1987).

Although these results have afforded some insight into the roles of the slave systems of WM in performance on mental arithmetic problems by adults, the picture with children, especially those younger than age 7 years, is even less clear. We do know that children use a range of strategies for solving arithmetic problems and that some of these strategies (even when used by adults) load heavily on WM resources (Hecht, 2002). At the basic level, children use fingers or other concrete referents to aid them in the counting process. From these simple strategies, children progress to auditory counting using the sum procedure (counting all numbers in the problem) to the min procedure (count-on the smallest number). Finally, children can retrieve arithmetic facts directly from LTM (see Siegler, 1999). Geary, Brown, and Samaranayake (1991) argued that for a representation of an answer to a specific arithmetic problem to become established in LTM, both the numbers presented in the problem and the answer must be simultaneously active in WM. Numerous studies now have shown that children who perform poorly in mathematics use immature counting strategies, take more time to solve calculation problems, commit more computational and memory-retrieval errors, and fail to shift from procedural-based problem solving (e.g., counting) to memory-based problem solving (e.g., fact retrieval, Bull \& Johnston, 1997; Bull, Johnston, \& Roy, 1999; Geary, 1990; Geary \& Brown, 1991; Geary et al., 1991; Geary, Bow-Thomas, \& Yao, 1992; Geary, Hamson, \& Hoard, 2000; Jordan \& Montani, 1997; Ostad, 1997). Some of these difficulties have been attributed to a lack of understanding of basic counting concepts, especially appreciating counting rules and knowledge of Arabic numbers (Geary et al. 1992; Geary, Hoard, \& Hamson, 1999; Geary et al., 2000)

However, WM resources are also known to influence the development of mathematic proficiency. Geary et al. (1991) found a numeric memory span advantage of approximately one digit for normally achieving children, and shorter memory span was related to more frequent computation errors. Because memory span is related to how quickly items can be retrieved from LTM and then articulated and rehearsed in the PL, it has been proposed that those children with mathematic difficulties count more slowly than normally 
achieving children when using counting strategies to solve arithmetic problems (Geary et al., 1991; Hitch \& McAuley, 1991). In children who use slow and inefficient counting methods, information may be lost from WM, and hence no representation (or a representation of an incorrect answer) is created in LTM. Thus, in a roundabout way, slower counting speed may be a manifestation of the observed fact-retrieval problems of children with mathematic difficulties.

It is interesting that this link between capacity of the PL (as measured by short-term memory (STM) span tasks such as digit and word span) and arithmetic has been called into question. In a number of studies, no association was found, or the association was not robust after statistically controlling for the influence of other cognitive skills. For example, Bull and Johnston (1997) found that if general speed of processing (measured by symbol matching and motor speed) was included in the model, there was no relation between STM and arithmetic. Furthermore, in a number of studies, children with mathematic difficulties show deficits on WM span tasks, particularly where the information has to be manipulated in some way before recall (e.g., Digits Backwards) and hence more likely under the control of the CE, rather than indicating a deficit in STM capacity per se (Passolunghi, Cornoldi, \& De Liberto, 1999; Swanson, 1994). Therefore, the role of the $\mathrm{CE}$, with functions such as attentional control and the updating of information in WM, may be of greater importance in supporting arithmetic proficiency in children, in comparison to adults.

Furthermore, because children only begin to spontaneously subvocally rehearse at about the age of 7 years (Baddeley, Gathercole, \& Papagno, 1998), younger children would have significant difficulty maintaining infor mation in the PL. If such rehearsal is age limited and if arithmetic performance is dependent on the storage of information in the PL, how can the finding be explained that even very young children (as young as 3 or 4 years) are able to complete sums (albeit very simple ones)? According to this developmental limitation, any verbally coded information, such as the addends of a sum, could not be rehearsed and, therefore, will be subject to rapid decay, preventing accurate computation. This inability to rehearse subvocally in the face of some computational ability necessarily implies that a component of WM other than the PL must be involved, at least in young children. Because direct retrieval of arithmetic facts is improbable in children this young, it is unlikely that $C E$ functions relating to the retrieval of information from LTM are involved heavily. However, other CE skills, such as the ability to attend to the appropriate aspects of information and switch between procedures, may be important if the child is using a reconstructive strategy. Moreover, the VSSP may be one critical component involved in young children's arithmetic, a fact overlooked in many early studies examining young children's skills in this domain.

Children's use of phonological versus visual-spatial encoding of information was examined in a study of immediate serial recall of line drawings
(Palmer, 2000). Children were asked to recall previously presented pictures chosen for either their visual or phonological similarity. The pictures were also labeled verbally or were unlabeled at presentation. Whereas older children benefited from labeling of pictures at presentation, younger children did not, suggesting that younger children could not make use of verbal codes stored in the PL. Furthermore, younger children tended to show visual similarity effects-that is, more difficulty recalling items that are visually similar (e.g., dog and goat) compared to older children. In contrast, recall in older children was more consistent with phonological similarity effects-that is, a difficulty recalling items that are alike in their phonological sound (e.g., room and spoon). Palmer concluded that young children progress from a period of purely visuo-spatial strategy use at around 4 years of age; through a stage of dual (visuo-spatial and verbal) strategy use; to an adultlike, mainly verbal strategy usage at the age of about 8 or 9 years, although this progression has not been investigated longitudinally. The transitional period of dual coding, Palmer suggests, is a critical time during which the CE is maturing (e.g., Baddeley, 1996), supporting flexible switching of strategies and recoding of visually presented material into a phonological form and vice versa.

The development of the cognitive processes that support retention of information in WM has rarely been directly studied in children during the performance of simple mental arithmetic. Davis and Bamford (1995) examined children's (aged 4-5 years) use of visual imagery in arithmetic performance, examining the solution of both simple problems (e.g., $1+1,2-1$ ) and more difficult problems (e.g., $6+2,8-1$ ). Children were presented with arithmetic problems that had contextual support-that is, concrete representations (in the form of small toys) for each number involved in the calculation-or had no visible concrete support, instead referring to hypothetical toys. Some of the children also were prompted to use an imagery strategy - that is, imagining a mental picture of the concrete representations. Davis and Bamford found that concrete contextual support led to the production of more correct answers. Furthermore, the children prompted in the use of the imagery strategy performed at an even higher level of accuracy. Therefore, it would appear that visual imagery does provide a useful resource in solving simple arithmetic problems, at least for young children. A number of studies also note that visual-spatial skills are an important contributor to mathematic ability (Casey, Nuttall, \& Pezaris, 1997; Geary, Saults, Liu, \& Hoard, 2000).

McKenzie, Bull, and Gray (2003) examined the cognitive mechanisms involved in children's mental arithmetic performance at age 6 and 8 years. By differentially disrupting phonological and visuo-spatial WM in younger and older children, they hoped to demonstrate different profiles of interference on arithmetic performance in the two age groups in comparison with a baseline arithmetic score. If younger children rely more on visuospatial strategies to perform simple arithmetic calculations (thereby supported by the VSSP), while older children depend more on verbal strategies 


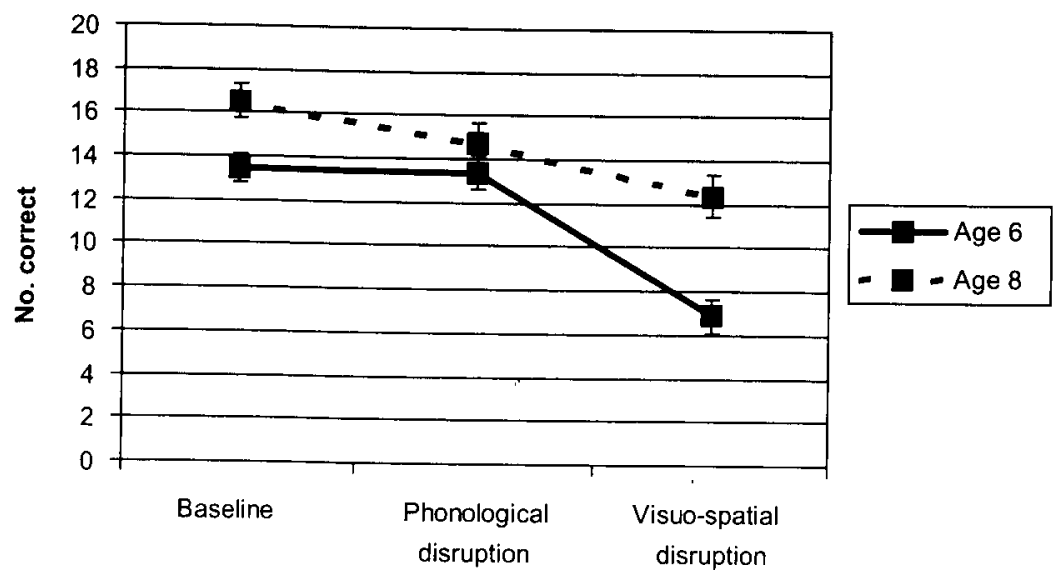

Arithmetic condition

FIGURE 4.1

Arithmetic performance of 6- and 8-year-old children under baseline conditions and with disruption to either the phonological loop or the visual-spatial sketchpad.

in calculation (supported by the PL), then, taken with Palmer's (2000) findings, the shift in strategy use from visual-spatial to verbal slave systems might not necessarily be task dependent; instead, it might reflect a general developmental phenomena that would apply more broadly to a range of tasks that require the storage and manipulation of information in WM. The PL and VSSP slave systems were disrupted by using two passive interference tasks: irrelevant speech and dynamic visual noise (DVN; McConnell \& Quinn, 2000), respectively. The results are shown in Figure 4.1. As predicted, DVN disrupted younger children's arithmetic performance, suggest ing that 6-year-old children rely on the VSSP to support simple arithmetic calculations. Listening to irrelevant speech, however, did not disrupt arith metic performance in younger children, in comparison to baseline performance. For older children, the results differed somewhat. Both DVN and listening to irrelevant speech interfered with arithmetic performance, suggesting that the older, 8-year-old children may rely on both the PL and VSSP to support calculation. Consistent with Palmer's (2000) speculation, the cognitive mechanisms recruited by children during arithmetic tasks appears to differ with age.

These results suggest that more attention should be given to the role of visual-spatial WM in children's developing mathematic competencies Clearly, such cognitive resources are being used to aid arithmetic performance and seem to be of critical importance to younger children, supporting Geary's et al. (1993) suggestion that spatial factors are more important for early mathematics abilities that are engaged less automatically or are in a rapid phase of acquisition. DVN can be selective in the nature of visuospatial functioning that it disrupts, with some authors concluding that DVN disrupts visual imagery or the vividness of visual images but not the actual storage of images within visual STM (Andrade, Kemps, Werniers, May, \& Szmalec, 2002; Baddeley \& Andrade, 2000). If DVN preferentially impairs visualization but not storage in children as well, then McKenzie et al.'s results suggest that young children are using the VSSP as a "workspace" where visual representations can be actively manipulated (an active visual buffer), rather than just as temporary storage of the information in a passive visual cache (see Pearson, 2001, and Pearson, Logie, \& Gilhooly, 1999 for a description of the distinction between the active visual buffer and the passive visual cache). The distinction between a visual buffer versus cache and the precise contributions of the visual-spatial and executive components to visualspatial WM task performance is being investigated in adults by Hamilton and his colleagues (Hamilton et al., 2003), and the ability to make use of both phonological and visual-spatial slave system resources should be fruitful targets of future investigations examining arithmetic and mathematic skills across development.

\section{THE CENTRAL EXECUTIVE}

Even at the early stages of examining the role of the PL in arithmetic proficiency, it was acknowledged that this relationship may be important because children with mathematic difficulties are less skilled in allocating their attention and in monitoring the problem-solving process-that is, in using the CE (Geary et al., 1991). Furthermore, results from studies are consistent with substantial overlap between performance on VSSP and CE measures, perhaps in part because many tasks used to measure the visual and spatial elements of the VSSP are also found to make demands on the attentional resources of the $\mathrm{CE}$. For example, verbal fluency, used to measure $\mathrm{CE}$ (e.g., Phillips, 1997) has been found to interfere considerably with performance on both visual and spatial span tasks in both children and adults (Hamilton et al., 2003). Therefore, the demonstrated link between either the PL or VSSP and arithmetic proficiency in children may be mediated by some kind of $\mathrm{CE}$ processing.

The consideration of $\mathrm{CE}$. functioning in relation to children's abilities has become relatively common in recent years. CE function has been investigated in numerous populations, including those with learning disabilities, language and comprehension problems, autism spectrum disorders, atten tion deficit/hyperactivity disorder (ADHD), and behavioral problems (e.g Adams, Bourke, \& Willis, 1998; Cornoldi, Barbieri, Gaiani, \& Zocchi, 1999 Hughes, 1998; Lorsbach, Wilson, \& Reimer, 1996; Ozonoff \& Jensen, 1999 Russell, Jarrold, \& Henry, 1996; Swanson, 1993, 1999; Swanson, Ashbaker 
$\&$ Lee, 1996). In school-age children and adolescents, mathematic skills also are related, at least in part, to CE functioning (Bull \& Scerif, 2001; Cirino Morris, \& Morris, 2002; Gathercole \& Pickering, 2000a; McLean \& Hitch, 1999). In adults, CE functions have been implicated in both simple and complex mental addition (e.g., Hecht, 1999, 2002; Logie et al., 1994; de Rammelaere, Stuyven, \& Vandierandonck, 2001), subtraction (e.g., Geary, Frensch, \& Wiley, 1993), multiplication (e.g., Seitz \& Schumann-Hengsteler, 2000 ); they also have been indirectly implicated in division (LeFevre $\bar{\alpha}$ Morris, 1999). More generally-that is, independent of mathematic proficiency-CE functions are involved in retrieval of information from LTM (Baddeley, 1996), planning (Duncan, 1986), inhibition of dominant actions (Diamond, 1989), dual-task performance (Baddeley, Bressi, Della Sala, Logie, $\&$ Spinnler, 1991), and switching of strategies (Duff $\&$ Logie, 2000).

One of the few studies to consider the role of WM in direct relation to children's classroom performance is that of Gathercole and Pickering (2000a), who studied early-elementary-aged children's mathematics performance on the National Curriculum assessments. The Working Memory Test Battery for Children (WMTB-C; Pickering \& Gathercole, 2001) was administered to a large cohort of 6- and 7-year-old children, with the aim of identifying those children performing below nationally expected levels. The results revealed a close link between performance on national curriculum assessments and WM skills. CE functioning, as measured by WM span tasks (i.e., counting, listening, and backward digit span) was found to be poorer for children performing below expected achievement levels compared with those performing at expected levels. These results are consistent with earlier findings by Geary et al. (1999) who reported that children with mathematic difficulties have more limited CE function, as indicated by poorer performance on a backward digit span task. Gathercole and Pickering argued that the importance of executive functioning is apparent informally if one considers the types of processing that occur day-to-day in the classroom, where the child continually must process new information and integrate it with information that has been retrieved from LTM or is being held in WM. Therefore, children with a restricted capacity to engage in such mental activities will fail to make adequate progress within school, although this argument speaks more generally to the role of CE skills in school achievement, not necessarily mathematics specifically.

In other studies, basic mathematic proficiency has been assessed through standardized, individually administered paper and pencil tests. Bull et al. (1999) found that 7-year-old children with poorer mathematic and arithmetic abilities also performed more poorly on a measure of $\mathrm{CE}$ functioning-the Wisconsin Card Sorting Test (WCST; Heaton, Chelune, Talley, Kay, $\&$ Curtiss, 1993). This test examines the ability to use feedback to determine criteria for sorting the cards and the ability to flexibly switch between criteria (e.g., shape, color, and number). It is interesting that children's difficulty on the WCST was restricted to perseverative errors; children of lower mathematic ability made more errors consistent with the previous conceptual set when the new set was active-that is, they found it more difficult to flexibly switch their sorting to a new criteria (e.g., sorting by shape) once one particular routine had become established (e.g., sorting by color). Rourke (1993) has reported similar findings, in the analysis of the types of errors made by children with specific mathematic learning disabilities, where one prominent error type was difficulty switching between psychological sets (e.g., from addition to subtraction problems). Bull et al. (1999) interpreted their results as suggesting a problem with $\mathrm{CE}$ functioning, specifically with inhibition of a prepotent response. Finally, in a sample of 1229 year-old children who scored below the $25 \%$ percentile of a standardized mathematic test, time to complete an auditory, written-visual, and color Trail Making Test were also related to arithmetic performance (McLean \& Hitch 1999). The authors concluded that both spatial WM span and switching between retrieval plans using the CE contributed to mathematic proficiency.

In a number of studies, the role of WM and CE functioning in solution of arithmetic word problems has been examined. CE attentional control skills are thought to be involved in arithmetic word problem solving because of the significant requirement for text comprehension, where incoming information must be integrated with the previous information maintained in WM for problem solution, and requires that the solver build a mental representation of that problem in WM (see Chapter 3 of this volume for further information on text comprehension and WM). Furthermore, the incoming problem information must be examined for its relevance and then selected or inhibited according to its importance for the solution of that problem. Swanson et al. (1993) measured WM span using a variant of the reading span task and found a significant positive correlation to the number of word problems that children solved.

However, a number of authors claim that differences in WM span may not be related to the quantity of information that can be held in memory but rather to the efficiency of inhibition of irrelevant, or no-longer-relevant, information from WM. Passolunghi et al. (1999) compared memory performance of children (aged approximately 9.5 years) who were either good or poor at problem solving, defined by their performance on short written word arithmetic problems. Good problem solvers had a significantly higher listening span and remembered significantly fewer non-final sentence words (i.e., irrelevant words) than poor problem solvers. Therefore, although both groups recalled overall similar numbers of words, good problem solvers were better able to inhibit irrelevant words and recall the last target word from each sentence, whereas the poor problem solvers struggled to inhibit the nonfinal words. Passolunghi and Siegel (2001) also found that children who were poor problem solvers demonstrated lower WM spans for material across a number of domains, not just for numeric information, as was found earlier (Siegel $\&$ Ryan, 1989), and these children who were less proficient had more 
difficulty inhibiting the no-longer-relevant or irrelevant information. Similar results have been reported in school-aged children with ADHD. Marzocchi, Lucangeli, De Meo, Fini, and Cornoldi (2002) administered word problems that contained no irrelevant information, irrelevant numeric information, or irrelevant verbal information. They hypothesized that any detrimental effects of the presence of the irrelevant information would occur during the procedural aspects of the computation, such as when choosing the appropriate procedures, because all pieces of relevant information need to be properly integrated using the CE resources of WM. Because the actual calculations presumably require simple fact retrieval without information integration, the irrelevant information was not presumed to affect calculation accuracy. Children with ADHD did indeed make more errors when the problems contained either irrelevant numeric information or irrelevant verbal information, with many of these errors in the procedural choice rather than in calculation accuracy.

\section{The Nature of the Central Executive}

Whether the CE plays a role in children's arithmetic is not in question. What is debated is how we should conceptualize the CE theoretically. This issue has implications for how the CE is assessed as well as on how it supports other cognitive abilities, such as children's mathematic proficiency. Although many researchers would agree that the CE does not have a unitary function (e.g., Miyake et al., 2000, Welsh \& Pennington, 1988), there remains considerable controversy regarding the specific constructs that are "executive" per se. Consistent with fractionated executive function models (e.g., Miyake et al., 2000), multiple CE functions are identified by factor analytic techniques; however, the components or factors are not usually completely independent; they share some common variance. Studies that have used factor analytic techniques to account for shared variance between test performance (e.g., principal components analysis, exploratory and confirmatory factor analysis) routinely identify WM and inhibition CE constructs (e.g., Espy, Kaufmann, and Glisky, 1999; Hughes, 1998; Miyake et al., 2000; Pennington, 1997) and commonly a flexibility or shifting CE construct (e.g., Espy et al., 1999; Hughes, 1998; e.g., Pennington, 1997; Welsh, Pennington, \& Groisser, 1991). One advantage of these factor analytic procedures is that individual test level data are reduced empirically to meaningful, shared CE constructs, which may better characterize their contribution to emergent mathematic abilities. One limitation of the studies already described (and many others in the field) is that the functions ascribed to the CE are often vague or isolated and are not tied to cognitive theory to better characterize and understand how CE difficulties might arise and what they might mean for mathematic proficiency. Often, only one genre of WM task is used (such as span tasks or measures of inhibition or measures of shifting ability), or only complex, global measures of $\mathrm{CE}$ function are selected that clearly require multiple cognitive abilities for performance (e.g., WCST, Tower tasks). Therefore, it is difficult to pinpoint the specificity or generality of the identified difficulties in CE function that relate directly to mathematic skills.

More recently, a number of researchers have aimed to focus more specifically on different components of $\mathrm{CE}$ functioning and their potential role in the development of children's arithmetic and mathematic skills. Based on theoretical, fractionated accounts of $\mathrm{CE}$. functioning, the main focus of attention has been on inhibition, shifting, and updating of information in WM From this perspective, inhibition may be needed to override information or routines that have been automatically activated from LTM and can be measured by tasks such as random generation where the participant is required to generate a random list of letters, trying to inhibit known sequences such as ABC, CIA, and so on (e.g., Baddeley, Emslie, Kolodny, \& Duncan, 1998), and the Stroop task, where participants must inhibit the automatic tendency to read a word to instead name the color of the ink in which the word is written (Stroop, 1935). However, inhibition also may be required to override a particular way of responding that may have been established within a task (e.g., stop sorting by color and start sorting by shape). Again, diffculties arise here in differentiating inhibition from shifting abilities; later in the chapter, this type of inhibitory process will be referred to as "conscious inhibition." Shifting ability is generally measured by complex tasks such as the WCST (Heaton et al., 1993) or the Dimensional Change Card Sort Task (Frye, Zelazo, \& Palfai, 1995). On these more complex tasks, there is much more interplay between processes for successful performance, including evaluation of the current strategy according to feedback provided, as well as on-line maintenance of the relevant dimension. This broad recruitment of different processes is supported by neuroimaging studies suggesting that a number of cortical areas are active during WCST performance (Berman et al., 1995) as well as other tasks of executive function (Collette et al., 1999). Despite these neuroimaging findings, cognitively, Miyake et al. (2000) found that WCST performance was predicted best by the ability to shift between strategies (measured by, for example, global-local, number-letter tasks) rather than by updating in WM (e.g., tone monitoring and letter memory tasks) or inhibition (e.g., antisaccade and stop-signal tasks).

Another CE feature is the capacity for the temporary activation of LTM, whereby the $C E$ encodes and retrieves information both from the PL and VSSP slave systems and from temporarily activated components of episodic LTM. This skill is measured through tasks such as Daneman and Carpenter's (1980) reading span task and the counting span task of Case et al. (1982), as used in the studies by Gathercole and Pickering (2000a, b). These tasks require the simultaneous processing and storage of information and do appear to allow the use of elaborate strategies to aid performance. Indeed, Towse and Hitch (1995) and Towse, Hitch, and Hutton (1998) account for individual differences on such tasks not in terms of resource sharing but in terms of task switching between the processing and maintenance aspects 
of the tasks, a dichotomy also supported by neuroimaging findings (Rypma, Berger, \& D’Esposito, 2002)

Complicating the use of these tasks to assess CE function is the fact that the overlap and interplay among these functions is large and deciding on the best methods to assess these skills is difficult. Consequently, many investigators resort to selecting specific tests in research batteries to measure salient CE functions on the basis of face validity alone. Because of the interrelated nature of $\mathrm{CE}$ function constructs, measures that are included to tap a single $C E$ function inevitably demand multiple $C E$ abilities for proficient performance. For example, other information is invariably inhibited (e.g. Diamond, 1985) to maintain information in WM for upcoming responding To flexibly shift responses in the light of conflicting rules requires maintaining the rule in mind and inhibiting prepotent, previous responses. Such interrelations make it difficult to assess the unique contributions of differing $\mathrm{CE}$ functions to outcomes, such as mathematic proficiency.

Using confirmatory factor analysis, Miyake et al. (2000) found that three target functions-namely, inhibition, shifting between mental sets and strategies, and updating of information in WM-were distinguishable, although not independent. Miyake et al. went on to suggest that unity among $C E$ functions may be accounted for by inhibition because all functions of the CE involve some inhibitory processes to properly guide and regulate cognition-for example, ignoring previous incoming information in a WM task, changing to a new mental set, and so on. Therefore, equating tests (e.g., WCST) to constructs (shifting) on the basis of face validity alone, rather than by using underlying measurement characteristics, can easily lead to erroneous conclusions because of the correlated nature of CE functions.

In an attempt to understand more fully the role of $C E$ functions in mathematics ability. Bull and Scerif (2001) administered a battery of CE measures to 7-year-old children who were under achieving and normally achieving in mathematics. Tasks were selected to map onto the main CE functions proposed by Miyake et al. (2000), including the WCST as an index of shifting ability, a number Stroop task to measure inhibition, and counting span to assess memory updating. Regression analyses revealed that all CE measures predicted unique variance in mathematics proficiency. Specifically, even after the variance associated with other $C E$ measures was controlled statistically in the model, CE measures of inhibition, shifting, and WM updating all accounted for additional, unique variance in mathematics
ability.

\section{Early Development of the Central Executive and} Mathematic Skills

In very young children-preschoolers and early kindergartners-it is even less clear whether CE functions are related to emergent mathematic abilities. Although some investigators have argued that simple mathematic skills are evident in infancy (e.g. Wynn, 1992), there is a marked emergence of informal mathematic skills (abilities that are not learned through formal instruction) during the preschool period. Gelman and Gallistel (1978), for example, have argued that preschool children possess a fundamental understanding of mathematic principles about counting, such as stable order, oneto-one correspondence, and cardinality, although young children may not fully understand the implications of these principles in various enumeration contexts (e.g., Geary, 1994; Sophian, 1996). There are significant changes in counting skills and arithmetic problem solving (e.g., Baroody, 1992; Sophian, 1996) and in spatial and geometric abilities (e.g., Newcombe \& Huttenlocher, 2000) during the preschool years, which provide the foundation for later mathematic knowledge and procedural competencies gained through formal schooling in the primary grades and beyond (Geary, 1994; Ginsburg, 1989; Rittle-Johnson \& Siegler, 1998).

During this same preschool period, there is a rapid development in the functions subserved by the $\mathrm{CE}$, such as inhibitory, memory updating, and flexible shifting skills (e.g., Diamond et al., 1997, Espy, 1997, Espy et al., 1999, Jacques \& Zelazo, 2001). Therefore, examining the relations between CE functions and emergent arithmetic skills in young children may provide insight into the shared ontogenetic organization of these abilities. One limitation that has hampered such endeavors in young children is the lack of available instruments to assess CE. functions because most standardized, general cognitive tools designed for preschool children do not adequately assess such abilities. Tasks adapted from developmental and cognitive neuroscience investigations offer one fruitul method by which to investigate CE functions (e.g., Diamond, 1985; Espy et al., 1999; Espy et al., 1999). Such tasks are advantageous because their relation to prefrontal cortical function has been established, at least in well-controlled studies with nonhuman animals or using similar neuroimaging paradigms with adult humans, and have demonstrated sensitivity in young children with various clinical disorders (Diamond et al., 1997; Espy, Kaufmann, \& Glisky, 1999; Espy, Kaufmann, Glisky, \& McDiarmid, 2001; Espy, McDiarmid, Senn, Cwik, \& Hamby, 2002). Such developmental cognitive neuroscience tasks (e.g., Diamond, 1985; Espy et al., 1999; Welsh \& Pennington, 1988) provide the potential to tap differing functions of the $C E$ that may have unique relations to emerging mathematics abilities in this very young age range.

Espy, McDiarmid. Cwik, Stalets, Hamby, and Senn (2004) aimed to determine whether $C E$ functions established empirically were related to emergent mathematic proficiency in preschool children. Two groups of children participated in this study: typically developing and preterm children at low neurobiologic risk, aged between 2 and 5 years. Although the two groups did not differ significantly in performance characteristics such as estimated $\mathrm{IQ}$, children born preterm are known to be at risk for arithmetic impairments (Hack, Klein, \& Taylor, 1995; Hunt, Cooper, \& Tooley, 1988). Therefore, these children served to provide a more variable range of mathematic 
ability. Additionally, there is emerging evidence of specific impairments in CE functions in children born preterm during the preschool period (e.g., Espy et al., 2002), in school age (Taylor et al., 1995), and into adolescence (Taylor et al., 2000). How such specific CE dysfunction in children born preterm contributes to more global outcomes, such as mathematic profciency, remains unclear.

CE functions, namely working memory, inhibitory control, and shifting, were determined empirically by conducting principal components analysis on the individual test-level data to identify meaningful CE components using the shared variance across individual,tests. In turn, these $\mathrm{CE}$ components were related using hierarchical regression analyses to emergent mathematic proficiency in preschool children, measured by the Applied Problems subtest from the Woodcock-Johnson-Revised Test of Academic Achievement (Woodcock \& Johnson, 1989). Inhibitory control, and to a lesser extent WM, contributed substantively to mathematic performance in these very young children. Specifically, the magnitude of the contribution of inhibitory control to early mathematic skills was large, even when the effects of child age, estimated child verbal intelligence, and maternal education level were controlled statistically. Furthermore, inhibitory control predicted emergent mathematics skills in preschoolers even when the influences of WM and shifting were removed, still accounting for $12 \%$ of mathematics skill variability. These findings provide a developmental link to similar relations between executive function and mathematic performance previously reported in school-age children (e.g., Bull \& Scerif, 2001; Gathercole \& Pickering, 2000; McLean \& Hitch, 1999). Given the differences in age range, methods used, and design between this study and others, the consistency of the relationship between executive functions and mathematic performance is persuasive.

The WM component also accounted for significant variance in early mathematic proficiency, when the influences of child age, estimated child verbal intelligence, and maternal education level were controlled, but not when the other $\mathrm{CE}$ functions were removed. In this age range, WM skills were correlated substantially with inhibitory control $(r=0.50, p<0.0001)$, limiting the amount of unique variance in emergent mathematic skills that could be accounted for by WM. It is interesting that shifting or mental flexibility did not contribute substantively to mathematics skills in very young children. These findings are in contrast to those reported for older, schoolage children (Bull \& Scerif, 2001; McLean \& Hitch, 1999). Mental flexibility may have contributed more to mathematics proficiency in school-age children, given the necessity for the older child to flexibly apply different mathematic procedures (e.g., borrowing, carrying) to obtain correct mathematic solutions. More complex mental flexibility skills also may be later developing and thus may be less related to mathematic abilities in very young children.

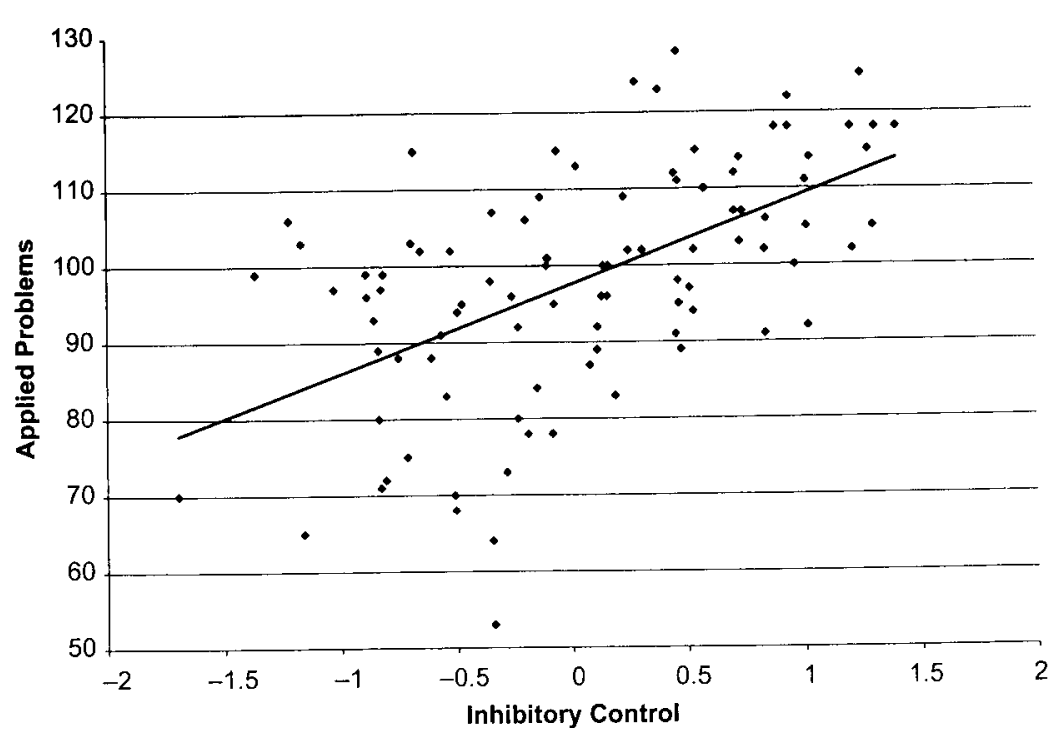

FIGURE 4.2

Woodcock-johnson-R Applied Problems standard score as a function of inhibitory control z-score in preschool children.

Children born preterm did score lower on the WM component in comparison to the typically developing children, consistent with a growing literature identifying weaknesses in WM in this population (e.g.. Espy et al., 2004, Luciana et al., 1999; Ross et al., 1992). Despite the observed performance difference, the nature of the relation between inhibitory control (in Figure 4.2) or WM and early mathematic abilities did not differ between typically developing preschoolers and those born preterm at low risk for neurodevelopmental sequelae. Both groups of preschool children, then, appear to utilize the CE functions, inhibitory control, and WM, in a comparable fashion to solve simple mathematic problems. Because of the attenuated relationship between WM and early mathematic proficiency in preschool children, compared with what has been reported elsewhere for school-age children, the deficits in WM reported for preschool children born preterm may not have much impact on functional outcomes such as mathematics in this age range.

Finally, preliminary results are presented from a longitudinal study conducted by Bull, Espy, \& Wiebel (in prep). Given that CE functions predict mathematic achievement in older children, and appear to be related to mathematics proficiency even in very young preschool children (Espy et al., 2004), can CE functions measured in preschoolers be used to identify those children who go on to develop specific difficulties in mathematics? 
Furthermore, given that basic number skills assessed early in development are good indicators of those children at risk for later mathematic difficulties (Geary et al., 1999, 2000), would assessment of CE functions provide additional utility in identification, beyond that of basic number skilis? In this study, CE functions were derived empirically through parsing of shared task variance with exploratory factor analysis. Similar to Espy et al. (2004), three factors were identified, which Bull et al. chose to refer to as "working memory updating," "automatic inhibition," and "conscious inhibition" (i.e. as would be required when a particular format of responding has been learned within a task and then had to be consciously inhibited)

Starting in 2000, 140 preschool children (mean age of 4.5 years) were administered the CE test battery and basic number knowledge was also assessed, including number recognition and writing (Arabic to verbal translation and vice versa), magnitude understanding, and basic knowledge of counting principles. Mathematic proficiency was measured by individually administered classroom assessments, namely the Performance Indicators in Primary School (PIPS; Tymms, 1999). The PIPS is conducted on entry to the first year of primary school (age 4-5), then again at the end of the firs (age 5-6), third (age 7-8), fifth (age 9-10), and the seventh year (11 years). Currently data are available for the first 2 of these testing periods. Children also completed the arithmetic subtest of the WPPSI during their preschoo year. Initial analyses examined the contribution of each CE component in predicting mathematics performance and the unique contribution to pre dicting mathematics ability after the other CE components had been taken into account statistically. Finally, the independent and unique contributions of the CE components were examined, after removing the variance in mathematics accounted for by basic number skills. Results are summarized in Table 4.1.

The top panel of the table indicates the contribution made by each component of executive functioning in predicting children's mathematics. WM updating and conscious inhibition account for large amounts of variance in mathematics ability when entered as the only predictor in the model However, when the variance associated with other CE functions has been controlled statistically (as shown in the second panel), only the WM component predicted unique variance in mathematics ability at both the early and later curriculum assessments.

Basic number skills accounted for a substantial amount of the variance in mathematics ability, particularly on the first PIPS assessment when the children were just entering primary school (as shown in the third panel of the table). The skills assessed at this first stage include basic number recognition, shape recognition, counting, and so on, resulting in considerable overlap with the basic number skills assessed in the preschool battery. Despite this large degree of overlap, the WM updating component was related to additional variance in mathematics proficiency on the PIPS, even after these basic number skills have been removed statistically.
TABLE 4.1

Preschool Executive Function and Basic Number Skills as Predictors of Mathematic Ability at Different Ages

\begin{tabular}{lccc}
\hline \multicolumn{2}{c}{$\begin{array}{c}\text { WPSSI Arithmetic } \\
\text { (Age 4) }\end{array}$} & PIPS Age 4-5 & PIPS Age 5-6 \\
\hline Independent Contribution of EFs & & \\
WM updating & $22.8^{* * *}$ & $36.3^{* * *}$ & $25.5^{* * *}$ \\
Automatic inhibition & $11^{*}$ & 8.8 & 5.8 \\
Conscious inhibition & $25.5^{* * *}$ & $20.5^{* *}$ & $21.5^{* * *}$ \\
Unique Contributions of EFs & & & \\
WM updating & $8.8^{*}$ & $15.9^{* *}$ & $9.6^{*}$ \\
Automatic inhibition & $7^{\mathrm{m}}$ & 0.4 & 4.4 \\
Conscious inhibition & $7.9^{\mathrm{m}}$ & 2.3 & 4.7
\end{tabular}

Independent Contributions of EFs Over and Above Variance Accounted for by Basic Number Skills

$\begin{array}{lccc}\text { Basic number skills } & 32.3^{* * *} & 56.7^{* * *} & 34.3^{* * *} \\ \text { WM updating } & 5.1 & 7.1^{* *} & 5.6^{\mathrm{m}} \\ \text { Automatic inhibition } & 4 & 0.3 & 3.4 \\ \text { Conscious inhibition } & 8^{*} & 1.9 & 5.8^{\text {m }}\end{array}$

Conscious inhibition

Unique Contribution of EFs Over and Above Variance Accounted for by Basic Number Skills and Other EF Skills

WM updating

Automatic inhibition

$6.8^{\mathrm{m}}$

$6.7^{*}$

1.6

Conscious inhibition

EF, executive functioning. Figures represent percentage of additional variance accounted for ${ }^{* * *} p<.001,{ }^{* *} p<.01,{ }^{*} p<.05, \mathrm{~m}=$ marginal significance $(p<.10)$

However, a word of caution is needed here. Different measures of mathematics proficiencies likely would yield a different pattern of results. The PIPS is an individually administered tool, designed to assess curricular progress. In terms of understanding the role of cognitive skills, such as CE functions in everyday outcome, using achievement measures that are more closely tied to performance in the classroom has real advantages in terms of greater ecologic validity. However, the nature of the assessmentthat is, individually administered versus group, standard based versus proficiency-might affect the nature of the cognitive abilities that support performance. These issues clearly merit careful thought and further study. Overall, these preliminary findings demonstrate that CE functions, in particular, WM updating, are related to mathematics proficiency and are important beyond basic number skills. Assessments that include both CE functions and basic number skills might be useful to identify at an early age those children who eventually evidence a specific mathematic disability. It will be interesting to see how CE functions assessed in very young preschool children relate to PIPS scores at age 7 years. At this age, the mathematic problems are more complex than those at the first stage of PIPS testing. The 
attention skills of inhibition and shifting may be a more prominent predictor of proficiency at this age, consistent with previous findings in school-age children (e.g., Bull \& Scerif, 2001; McLean \& Hitch, 1999; Gathercole \& Pickering, 2000a)

Although we have tried to focus on the communality in findings, clearly some results are contradictory, particularly between those in preschool versus school age children, and those within an age range that use different types of mathematics assessments, for example, Espy et al. (2004) versus Bull et al. (in prep). It is likely that at least some of these differences result from the tools used to assess CE functions across studies and ages. In Espy et al., many of the tasks used to assess inhibitory control required inhibition or suppression of a prepotent motor response-for example. pushing a button when a target animal is presented, but not pressing the response key when the animal's sound is paired with the incorrect animal picture; maintaining a still posture despite distractions; inhibiting reaching for an enticing gift; and inhibiting searching at a previously rewarded location. In contrast, Bull et al. used inhibitory tasks that demanded a stronger "cognitive" inhibitory component, such as the Stroop Interference, and its preschool variant, the Day/Night Stroop (Gerstadt, Hong, \& Diamond, 1994). Relations between the more primitive, "motorically" based inhibitory control and the more "cognitive" inhibition are not clear. Although Ruff and Rothbart (1996) conceptualize the motoric inhibitory control as a developmental precursor to the cognitive inhibition, such relations have not been demonstrated empirically. Until such relations are clarified with longitudinal designs, the ontogenetic relation between inhibitory control and the development of mathematic competency cannot be elucidated fully.

Similarly, the role of shifting (also referred to as cognitive flexibility or conscious inhibition) differs across studies. In preschool children, shifting was unrelated to mathematics performance in both Espy et al. and Bull et al. Measuring cognitive flexibility in preschool children has proved to be challenging because reversal task performance may discriminate only those with severe disturbances in flexibly shifting between response sets, such as children diagnosed with severe disorders (McEvoy, Rogers, \& Pennington, 1993). Other measures that focus on concept formation may prove to be more useful in this regard (e.g., Smidts, Jacobs, \& Anderson, 2004; (Jacques $\&$ Zelazo, 2001). Furthermore, as noted by Espy et al. and in line with findings from school-age children (Bull et al., 1999; Bull \& Scerif, 2001; McLean \& Hitch, 1999), the ability to shift flexibly, or consciously inhibit certain procedures or information, may be more critical for performance on more complex mathematic problem solving that is not assessed until later in elementary school. Mathematics problems for preschool children involve counting and simple regrouping, that, at least on the surface, do not demand as much WM updating to achieve adequate proficiency as problems that involve carrying and borrowing, which are more typical in early elementary school grades. In fact, most of the early items from the WJ-R Applied Prob- lems subtest can be solved with knowledge of small quantity numbers (National Institute of Child Health and Human Development, 2002), and early items on the PIPS assessment only assess very basic number skills and counting. It is not surprising that more proficient performance on these simple problems may require more basic inhibitory control or maintenance in a short-term storage system, perhaps with the CE performing the role of coordinating representations of the information being held in the slave systems. Using multiple measures of mathematic abilities and assessing mathematic proficiencies longitudinally is clearly critical in determining how CE functions are related to the dynamic development of mathematics skills.

One important strength of the approach used by both Espy et al. and Bull et al. is the empirical derivation of the CE components. Three components were extracted in each study, labeled as Working Memory, Inhibitory Control (automatic inhibition), and Mental Flexibility (shifting, conscious inhibition), consistent with other studies in older children (e.g., Kelly, 2000; Lehto, Juujarvi, Kooistra, \& Pulkkinen, 2003; H.S. Levin, et al., 1996; Pennington, 1997; Welsh, et al., 1991). Although these observed measurement patterns were derived empirically, the labels applied are a matter of individual preference and judgment. The labels were applied on the basis of previous findings and historical context; however, other labels from other frameworks might also easily describe the derived factors. However, an important limitation of this approach is that the observed loading pattern is test specificthat is, a different loading pattern may be evident if different tests, or even different variables scored from the same test, had been included in the statistical models. What is needed are systematic studies that use measurement model approaches to better characterize CE function organization in children (e.g., confirmatory factor analysis), similar to that initiated by Miyake et al. (2000) in college students, because structural equation modeling approaches can more accurately represent the relations among observed test performance and latent constructs. Only by understanding CE organization in different age ranges will it be possible to better describe the resultant relations to other functional outcomes, such as mathematics proficiency.

The relation between executive function and mathematic proficiency suggests an important role of prefrontal systems in this age range, consistent with findings from imaging studies in adults and children relating various mathematics skills and frontal lobe function (Fullbright et al. 2000; Gruber Indefrey, Steinmetz, \& Kleinschmidt, 2001; Levin et al., 1996; Menon, Riveria, White, Glover, Reiss, 2000; Miles \& Stelmack, 1994; Prabhakaran, Rypma, \& Gabrieli, 2001; Zago et al., 2001). However, without direct measurement of brain function and concurrent behavioral assessment in this age range, the specific areas that contribute to emergent mathematic proficiency in children are unknown. Because of the technical limitations of the use of functional imaging methods with young children, high-density sensor 
array event-related potential methods may be a more suitable tool by which to examine such relations.

More generally, the use of developmental and cognitive neuroscience paradigms in the assessment of CE functions offers the opportunity to better assess more discrete neuropsychological skills that are related to functional outcomes, such as emergent mathematic proficiency. Such methods are particularly appealing because relations of test performance to specific brain areas may be stronger than more traditional general ability (e.g., intelligence) measures. Although the neuropsychological structure in young children is likely to be less differentiated than in older children, these methods are useful in highlighting CE performance discrepancies that relate to functional academic outcome. Even in modern investigations that focus on direct brain measurement with highly specialized and technical methods, the careful description of behavior-behavior relations across the developmental context (Fletcher \& Taylor, 1984) is still of central relevance today if we are going to try and pin down the exact nature of the CE functions that underlie poor mathematics skill development.

\section{WHAT ARE THE IMPLICATIONS FOR EDUCATION?}

When solving an arithmetic or mathematic problem, it is clear that WM may be involved at a number of stages. Solving virtually any arithmetic or mathematic problem will require the solver to hold information in memory, through the use of verbal or visual-spatial codes that use the slave systems. Studies examining the slave systems revealed that children make differential use of visual-spatial and verbal codes at different points throughout development, which may have important implications for the methods of presenting and teaching mathematic skills to children.

The ability to hold, manipulate, and update information in WM has been found to be of crucial importance for the mathematic performance of children of all ages. Difficulty updating information in memory may occur if the child is unable to efficiently retrieve information from LTM to support that being held in short-term storage. Furthermore, the child may have to select and integrate the relevant and critical information, abilities that are likely to be dependent on inhibition and short-term maintenance and manipulation of information. Particularly where tasks contain even small amounts of irrelevant information, children may have difficulty not in selecting the appropriate information, but in inhibiting the inappropriate information that is not relevant to the context at hand. WM may then be overloaded, resulting in difficulty completing the procedural aspects of the task. Finally, shifting ability, or mental flexibility, has been found to play an important role in the mathematics performance of older children, where more complex mathematic tasks such as multi-digit addition and multiplication may require the child to shift between procedures and interim solutions, or even shift between multiplying and adding if decomposition strategies are being used. Similarly, shifting also may be required for carrying operations in complex arithmetic. Therefore, mathematic skills require not only basic storage functions involving the WM slave systems, but also the attentional control functions of the CE.

In the classroom, there might be ways in which the memory load, or the need to recruit $C E$ resources, can be reduced to improve children's performance and learning. Use of external representations reduces load on WM during activities such as learning and problem solving. Frequent revision will mean that concepts needed to provide meaning to new information will be readily available in LTM. Hence, retrieval will be more efficient and the processing load placed on LTM will be lower. Presenting information in a more logical sequence also may make information processing more effcient. Children who may rely more on VSSP as a workspace for calculation may be aided by adjusting the mode of presentation from verbal to visual (Riding, Grimley, Dahraei, \& Banner, 2003). It may also be possible to devise strategies for increasing the inhibition of irrelevant information. For example, children could be made more aware of the types of irrelevant information that may interfere with problem solving. Alternatively, children could be taught to underline relevant information, cancel out the irrelevant information, and differentially rehearse the two types of information (Marzocchi, et al., 2002).

Can CE function skills be improved with training? Dowsett and Livesey (2000) found that repeated exposure to tasks facilitating the acquisition of increasingly complex rule structures (such as card sorting tasks) resulted in improved inhibitory control in children as young as 3 years of age. They argued that experience with such tasks increased the acquisition of complex rules by placing demands on CE functions, including response control (of actions and attention), representational flexibility, maintenance of information in WM, and proficiency at error detection. What we do not know is whether any gains made through CE training generalize to other contexts or have a secondary benefit on those skills that we know depend to a large extent on CE functions, such as mathematics.

Do WM assessments at school entry provide accurate prospective indicators of failure to reach normal levels of attainment at later points in the educational process? Compared to assessments of basic concepts (e.g., early number skills), which might be heavily influenced by cultural factors and the quantity and quality of environmental support, WM assessments would be likely to be novel to all children. Hence, such additional assessments may be a useful supplement to existing evaluation using knowledge-based methods for identification of at-risk children (Gathercole \& Pickering, 2000a). Certainly, the findings from Bull et al. (in prep) and Espy et al. (2004) provide indirect support for utility of such assessments at a young age. The next obvious step is to use advances in our theoretical and practical understanding of WM and the educational, curricular knowledge and teacher 
expertise to devise large-scale screening and pilot intervention studies to determine the true utility of such approaches in identifying children at risk for difficulties in mathematic achievement. Because of the protracted development of WM abilities and the changing nature of the mathematic skills that need to be acquired by children at different ages, longitudinal studies will need to be constructed carefully to more fully address this issue.

\section{Summary Box}

- Cognitive limitations in childhood do lead to difficulties in learning basic arithmetic and mathematic skills, and we need to pinpoint these cognitive limitations if we are to help children in their learning.

- Mathematic skills are supported by verbal and visual-spatial STM resources, the reliance on which may vary depending on age and experience.

- Children of poorer mathematics ability find it more difficult to inhibit irrelevant information and stay focused on the task at hand.

- Children of poorer mathematics ability find it more difficult to update information in WM and to flexibly switch from one established strategy to another.

- The nature of executive abilities remains to be fully defined and operationalized, particularly for young children.

- Different executive abilities relate to mathematics achievement at different ages and at varying levels of mathematics complexity.

- Executive abilities relate to mathematics differently in typically and atypically developing populations.

- Using a combination of subject specific tasks and general WM tasks, it may be possible to identify children at risk of developing mathematic difficulties.

- A deeper understanding of the cognitive limitations will help us to develop teaching strategies to overcome or circumvent these difficulties.

\section{References}

Adams, A. M., Bourke, L., \& Willis, C. (1998, September). Working memory: Implications for individual differences in language development. Poster presented at the British Psychological Society Developmental Section Annual Conference. Lancaster, England

Andrade, J. Kemps, E. Werniers, Y., May, J., \& Szmalec, A. (2002). Insensitivity of visual shortterm memory to irrelevant visual information. Quarterly Journal of Experimental Psychology, $55 A, 753-774$

Baddeley, A D. (1986). Working Memory. Oxford: Oxford University Press
Baddeley, A. D. (1996). Exploring the central executive. Quarterly Journal of Experimental Psychology, 49A, 5-28.

Baddeley A. D (1999) Essentials of Human Memory. Hove: Psychology Press.

Baddeley, A. D. (2000). The episodic buffer: a new component of working memory? Trends in Cognitive Science, 4, 417-423.

Baddeley, A. D., \& Andrade, J. (2000). Working memory and the vividness of imagery. Journal of Experimental Psychology: General, 129, 126-145

Baddeley, A D. Bressi, S. Della Sala S Logie R \& Spinnler. H. (1991). The decline of working memory in Alzheimer's disease: A longitudinal study. Brain, 114, 2521-2542.

Baddeley, A. D., Emslie, H., Kolodny, J., \& Duncan, J. (1998). Random generation and the executive control of working memory. Quarterly journal of Experimental Psychology, 51A, $819-852$

Baddeley, A. D., \& Hitch, G. J. (1974). Working memory. In G. A Bower (Ed.), Recent advances in learning and motivation (Vol. 8, pp. 47-90). New York: Academic Press

Baddeley A D. Garhercole S \& Papagno, C. (1998). The phonological loop as a language learning device. Psychological Review, 105, 158-173

Badian, N. A. (1983). Dyscalculia and nonverbal disorders of learning. In H. R. Myklebust (Ed.) Progress in Learning Disabilities. New York: Stratton

Baroody, A. 1. (1992). The development of preschoolers' counting skills and principles. In J. Bideau, C. Meljac, \& J. Fischer (Eds.), Pathways to number (pp. 99-126). Hillsdale. $\mathrm{NJ}$ : Erlbaum.

Berman, K. F, Ostrem, J. L., Randolph, C., Gold. J., Goldberg, T. E., Coppola, R., et al. (1995) Physiological activation of a cortical network during performance on the Wisconsin Card Sorting test: A positron emission tomography study. Neuropsychologica, 33 1027-1046.

Bull, $R$, Espy, K A \& Wiebe, S (in prep). Executive function skills as longitudinal predictors of children's mathematics ability

Bull, R, \& Johnston, R. S. (1997). Children's arithmetical difficulties: Contributions from processing speed, item identification, and short-term memory. Journal of Experimental Child Psychology, 65, 1-24.

Bull, R., Johnston, R. S., \& Roy, J. A. (1999). Exploring the roles of the visual-sparial sketch pad and central executive in children's arithmetical skills: Views from cognition and developmental neuropsychology. Developmental Neuropsychology, 15(3), 421-442.

Bull, R. \& Scerif, G. (2001). Executive functioning as a predictor of children's mathematics ability: Inhibition, switching, and working memory. Developmental Neuropsychology, 19, 273-293.

Case, R., Kurland, D. M., \& Goldberg, J (1982). Operational efficiency and the growth of shortterm memory span. Journal of Experimental Child Psychology. 33(3), 386-404

Casey, M. B. Nuttall, R. \& Pezaris, E. (1997). Mediators of gender difference in mathematics college entrance scores: A comparison of spatial skills with internalized beliefs and anxieties. Developmental Psychology, 33, 669-680

Cirino, P. T., Morris, M. K. \& Morris, R. D. (2002). Neuropsychological concomitants of calculation skills in college students referred for learning difficulties. Developmental Neuropsy chology, 21, 201-218.

Colletre, F., Salmon, E., Van der Linden, M., Chicherio, C., Belleville, S., Degueldre, C., et al (1999) Regional brain activity during tasks devored to the central executive of working memory. Cognitive Brain Research, 7, 411-417.

Cornoldi, C., Barbieri, A., Gaiani, C., \& Zocchi, S. (1999). Strategic memory deficits in attention deficit disorder with hyperactivity participants (ADHD): The role of executive processes Developmental Neuropsychology, 15, 53-71

Daneman, M. \& Carpenter, P. A. (1980). Individual differences in working memory and reading Journal of Verbal Learning and Verbal Behaviour, 19,450-466

Davis, A. \& Bamford, G. (1995). The effect of imagery on young children's ability to solve simple arithmetic. Education Section Review, 19,61-68 
Dehaene. S. (1992). Varieties of numerical abilities. Cognition. 44, 1-42.

de Rammelaere, S., Stuyven, E., \& Vandierendonck, A. (2001). Verifying simple arithmetic sums and products: Are the phonological loop and the central executive involved? Memory $\&$ Cognition, 29, 267-273.

Diamond, A. (1989). The development and neural bases of higher mental functions. New York: New York Academy of Science.

Diamond. A. (1985). Development of the ability to use recall to guide action, as indicated by infants' performance on AB. Child Development, 56, 868-883.

Diamond, A., Prevor, M. B.. Callender. G., \& Druin, D. P. (1997). Prefrontal cortex cognitive deficits in children treated early and continuously for PKU. Monographs of the Society for Research in Child Development, 62, 1-205.

Dowsett, S. M., \& Livesey, D. J. (2000). The development of inhibitory control in preschool children: Effects of "executive skills" training. Developmental Psychobiology, 36, 161-174

Duncan, J. (1986). Disorganization of behaviour after frontal lobe damage. Cognitive Neuropsychology, 3, 271-290

Duff, S. C. \& Logie, R. H. (2000). Processing and storage in working memory span. Quarterly Journal of Experimental Psychology, 54A, 31-48.

Espy, K. A. (1997). The shape school: Assessing executive function in preschool children. Developmental Neuropsychology, 13, 495-499.

Espy, K. A., Kaufmann, P. M., \& Glisky, M. L. (1999). Neuropsychological function in toddlers exposed to cocaine in utero: A preliminary study. Developmental Neuropsychology, 15 , $447-460$.

Espy, K. A., Kaufmann, P. M., Glisky, M. L., \& McDiarmid, M. D. (2001). New procedures to assess executive functions in preschool children. The Clinical Neuropsychologist, 15, $46-58$.

Espy, K. A., Kaufmann. P. M., McDiarmid, M. D.. \& Glisky. M. L. (1999). Executive functioning in preschool children: Performance on $A-n o t-B$ and other delayed response format tasks. Brain and Cognition, 41, 178-199.

Espy, K. A., McDiarmid, M. D., Cwik, M. F., Stalets, M. M. Hamby, A., \& Senn, T. E. (2004). The contribution of executive functions to emergent mathematics skills in preschool children. Developmental Neuropsychology, 26, 465-486.

Espy, K. A., Stalets, M. M., McDiarmid, M. D., Senn, T. E., Cwik, M. F. \& Hamby, A. F. (2002) Executive functions in preschool children born preterm: Applications of cognitive neuroscience paradigms. Child Neuropsychology, 8, 83-92.

Fletcher, J. M., \& Taylor, H. G. (1984). Neuropsychological approaches to children: Towards a developmental neuropsychology. Journal of Clinical Neuropsychology, 6, 39-56

Frye, D., Zelazo, P. D., \& Palfai, T. (1995). Theory of mind and rule-based reasoning. Cognitive Development, 10, 483-527.

Fullbright, R. K., Molfese, D. L., Stevens, A. A., Skudlarski, P., Lacadie, C. M., \& Gore, J. C. (2000). Cerebral activation during multiplication: A functional MR imaging study of number processing. American Journal of Neuroradiology, 21, 1048-1054

Gathercole, S. E., \& Pickering. S. J. (2000a). Working memory deficits in children with low achievements in the national curriculum at 7 years of age British Journal of Educational Psychology. 70, 177-194

Gathercole, S. E. \& Pickering, S. J. (2000b). Assessment of working memory in six- and sevenyear-old children. Journal of Educational Psychology. 92, 377-390.

Geary, D. C. (1990). A componential analysis of an early learning deficit in mathematics. Journal of Experimental Child Psychology, 49, 363-383.

Geary, D. C. (1994). Children's Mathematical Development. Washington, DC: American Psychological Association

Geary, D. C., Bow-Thomas, C. C., \& Yao, Y. (1992). Counting knowledge and skill in cognitive addition: A comparison of normal and mathematically disabled children. Journal of Experimental Child Psychology, 54, 372-391.
Geary, D. C., \& Brown, S. C. (1991). Cognitive addition: Strategy choice and speed of processing differences in gifted, normal, and mathematically disabled children. Developmental Psychology, 27, 398-406.

Geary, D. C., Brown, S. C., \& Samaranayake, V. A. (1991). Cognitive addition: A short longitudinal study of strategy choice and speed-of-processing differences in normal and mathematically disabled children. Developmental Psychology, 27, 787-797.

Geary, D. C., \& Burlingham-Dubree, M. (1989). External validation of the strategy choice model for addition. Journal of Experimental Child Psychology, 47, 175-192.

Geary, D. C., Frensch, P. A., \& Wiley, J. G. (1993). Simple and complex mental subtraction: Strategy choice and speed-of-processing differences in younger and older adults. Psychology and Aging, 8, 242-256.

Geary, D. C., Hamson, C. O., \& Hoard, M. K. (2000). Numerical and arithmetical cognition: A longitudinal study of process and concept deficits in children with learning disability. Journal of Experimental Child Psychology, 77, 236-263.

Geary, D. C., Hoard, M. K., \& Hamson, C. O. (1999). Numerical and arithmetical cognition: Patterns of functions and deficits in children at risk for a mathematical disability. Journal of Experimental Child Psychology, 74, 213-239.

Geary, D. C., Saults, S. J., Liu, F., \& Hoard, M. K. (2000). Sex differences in spatial cognition. computational fluency, and arithmetical reasoning. Journal of Experimental Child Psychology, $77,337-353$.

Gelman, R., \& Gallistel, C. R. (1978). The Child's Understanding of Number. Washington, DC. American Psychological Association.

Gerstadt, C. L., Hong, Y. J., \& Diamond, A. (1994). The relationship between cognition and action: Performance of children $31 / 2-7$ years on a Stroop-like day-night test. Cognition. 53 , $129-153$.

Ginsburg, H. P. (1989). Children's Arithmetic, $2^{\text {nd }} E d$. Cambridge, MA: Harvard University Press Gross-Tsur, V., Manor, O., \& Shalev. R. S. (1996). Developmental dyscalculia: Prevalence and demographic features. Developmental Medicine and Child Neurology, 38, 25-33.

Gruber, O. Indefrey, P., Steinmetz. H., \& Kleinschmidt, A. (2001). Dissociating neural correlates of cognitive components in mental calculation. Cerebral Cortex, 11(4), 350-359.

Hack, M., Klein, N. K., \& Taylor, H. G. (1995). Long-term developmental outcomes of low birth weight infants. The Future of Children, 5, 176-196.

Hamilton, C. J., Coates, R. O., \& Heffernan, T. (2003). What develops in visuo-spatial working memory development? European Journal of Cognitive Psychology, 15. 43-69.

Hartje, W. (1987). The effect of spatial disorders on arithmetical skills. In G. Deloche $\&$ X. Seron (Eds.), Mathematical disabilities: A cognitive neuropsychological perspective. (pp. 121-135). Hillside. NJ: Lawrence Erlbaum Associates.

Hayes, J. R. (1973). On the function of visual imagery in elementary mathematics. In W. G. Chase (Ed.), Visual information processing (pp. 177-214). New York: Academic.

Heathcote, D. (1994). The role of visuo-spatial working memory in the mental addition of multidigit addends. Current Psychology of Cognition, 13, 207-245.

Heaton, R. K., Chelune, G. J., Talley, J. L., Kay, G. G., \& Curtiss, G. (1993). Wisconsin Card Sorting Test manual. Odessa. FL: Psychological Assessment Resources.

Hecht, S. (1999). Individual solution processes while solving addition and multiplication math facts in adults. Memory and Cognition, 27, 1097-1107.

Hecht, S. A. (2002). Counting on working memory in simple arithmetic when counting is used for problem solving. Memory and Cognition. 30, 447-455.

Hitch, G. J. (1978). The role of short-term working memory in mental arithmetic. Cognitive Psychology, 10, 302-323.

Hitch, G. J., \& McAuley, E. (1991). Working memory in children with specific arithmetical learning difficulties. British Journal of Psychology, 82, 375-386.

Hughes, C. (1998). Executive function in preschoolers: Links with theory of mind and verbal ability. British Journal of Developmental Psychology, 16, 233-253. 
Hunt, J. V., Cooper, B. A. B., \& Tooley, W. H. (1988). Very low birth-weight infants at 8 and 11 years of age. Role of neonatal iliness and family status. Pediatrics, 82, 596-603.

Hunter, I. M. L. (1957). Memory: Facts and fallacies. Baltimore: Penguin.

Jacques, S., \& Zelazo, P. D. (2001). The Flexible Item Selection Task (FIST): A measure of executive function in preschoolers. Developmental Neuropsychology, 20, 573-591.

Jordan, N. C., \& Montani, T. O. (1997). Cognitive arithmetic and problem solving: A comparison of children with specific and general mathematics difficulties. Journal of Learning Disabilities, 30, 624-634

Kelly, T. P. (2000). The development of executive function in school-aged children. Clinical Neuropsychological Assessment, 1, 38-55.

Kosc. L. (1974). Developmental dyscalculia. Journal of Learning Disabilities, 7, 164-177.

LeFevre, I. \& Morris, J. (1999). More on the relation between division and multiplication in simple arithmetic: Evidence for mediation of division solutions via multiplication Memory and Cognition, 27, 803-812

Lehto, J. E., Juujarvi. P., Kooistra. L., \& Pulkkinen, L. (2003). Dimensions of executive functioning: Evidence from children. British Journal of Developmental Psychology, 21 $59-80$

Levin, H., Fietcher, J., Kufera, J., Harward, H., Lilly, M. Mendelsohn, D. et al. (1996). Dimensions of cognition measured by the Tower of London and other cognitive tasks in headinjured children and adolescents. Developmental Neuropsychology. 12. 17-34.

Levin, H. S., Scheller, J., Grafman, J., Martinkowski, K., Winslow, M., \& Mirvis, S. (1996). Dyscalculia and dyslexia after right hemisphere injury in infancy. Archives of Neurology, 53(1), $88-96$

Lewis, C Hitch G \& \& Walker P (1994). The prevalence of specific arithmetic difficulties and specific reading difficulties in 9- to 10-year-old boys and girls. Journal of Child Psychology and Psychiatry, 35, 283-292.

Logle, R. H. (1986). Visuo-spatial processing in working memory. Quarterly fournal of Experi mental Psychology, 38A. 229-247.

Logie. R. H. (1995). Visuo-spatial working memory. Hove: UK. Lawrence Erlbaum Associates

Logie, R. H., Gilhooly, K. J.. \& Wynn, V. (1994). Counting on working memory in arithmetic problem solving. Memory and Cognition, 22, 395-410.

Logie, R. H., \& Marchetti, C. (1991). Visuo-spatial working memory: Visual, spatial or centra executive? In Logie R. H., Denis M. (Eds.), Mental Images in Human Cognition, pp 105-115. Amsterdam: Elsevier Science Publishers BV.

Lorsbach, T. C., Wilson, S., \& Reimer, J. F. (1996). Memory for relevant and irrelevant information: Evidence for deficient inhibitory processes in language/learning disabled children Contemporary Educational Psychology, 21, 447-466.

Luciana, M. Lindeke, L., Georgieff, M.. Mills, M., \& Nelson, C. A. (1999). Neurobehavioral evidence for working memory deficits in school-aged children with histories of prematurity Developmental Medicine and Child Neurology, 41,521-533.

Marzocchi, G. M., Lucangeli, D., De Meo, T., Fini, F., \& Cornoldi, C. (2002). The disturbing effect of irrelevant information on arithmetic problem solving in inattentive children. Developmental Neuropsychology, 21, 73-92.

McConnell, J., \& Quinn, J. G. (2000). Interference in visual working memory. Quarterly Journal of Experimental Psychology, 53A, 53-67

McEvoy, R. E., Rogers, S. J., \& Pennington, B. F. (1993). Executive function and social com munication deficits in young autistic children. Journal of Child Psychology and Psychiatry. $34,563-578$.

McKenzie, B. Bull, R, \& Gray, C. (2003). The effects of phonological and visual-spatial interference on children's arithmetic performance. Educational and Child Psychology, 20, 93-108.

McLean, J. F. \& Hitch, G. J. (1999). Working memory impairments in children with specific arithmetic learning difficulties. Journal of Experimental Child Psychology, 74, 240-260.

Meiser, T., \& Klauer, K. C. (1999). Working memory and changing-state hypothesis. Journal of Experimental Psychology: Learning. Memory. and Cognition, 25, 1272-1299.
Menon, V Riveria S M White, C. D. Glover G. H. \& Reiss, A L. (2000) Dissociating pre frontal and parietal cortex activation during arithmetic processing. Physical Review Letters, 85(3), 520-524.

Miles, J., \& Stelmack. R. M. (1994). Learning disability subtypes and the effects of auditory and visual priming on visual event-related potentials to words. Journal of Clinical \& Experimental Neuropsychology, 16(1), 43-64

Miyake, A., Friedman, N. P., Emerson, M. J., Witzki, A. H., Howerter, A., \& Wager. T. D. (2000) The unity and diversity of executive functions and their contributions to complex frontal lobe tasks: A latent variable analysis. Cognitive Psychology, 41, 49-100

Miyake, A., Friedman, N. P., Rettinger, D. A., Shah, P., \& Hegarty, M. (2001). How are visuospatial working memory, executive functioning, and spatial abilities related? A latent variable analysis. Journal of Experimental Psychology: General, 130, 621-640.

Miyake, A., \& Shah, P. (1999). Models of working memory: Mechanisms of active maintenance and executive control. Cambridge, UK: Cambridge University Press

National Institute of Child Health and Human Development. (2002). Workshop. Early Childhood Education and School Readiness. October, Baltimore.

Newcombe, N., \& Huttenlocher, J. (2000). Making Space: The development of spatial representation and reasoning. Cambridge, MA: MIT Press

Noel, M. P., Desert, M., Aubrun, A., \& Seron, X. (2001). Involvement of short-term memory in complex mental calculation. Memory and Cognition, 29, 34-42.

Ostad. S. A. (1997). Developmental differences in addition strategies: a comparison of mathematically disabled and mathematically normal children. British Journal of Educational Psychology, 67, 345-357.

Ozonoff, S., \& Jensen, J. (1999). Brief report: Specific executive function profiles in three neurodevelopmental disorders. Journal of Autism and Developmental Disorders. 29. $171-177$.

Palmer, S. (2000). Working memory: A developmental study of phonological recoding. Memory, 8, 179-193.

Passolunghi, M. C., Cornoldi, C., \& De Liberto. S. (1999). Working memory and intrusions of irrelevant information in a group of specific poor problem solvers. Memory and Cognition. 27(5), 779-790

Passolunghi, M. C., \& Siegel, L. S. (2001). Short-term memory, working memory, and inhibitory control in children with difficulties in arithmetic problem solving. Journal of Experimental Child Psychology, 80, 44-57

Pearson, D. G. (2001). Imagery and the visuo-spatial sketch pad. In J. Andrade (Ed.), Working memory in perspective (pp. 33-59). Hove, UK: Psychology Press.

Pearson, D. G., Logie, R. H., \& Gilhooly, K. J. (1999). Verbal representations and spatial manipulation during mental synthesis. European Journal of Cognitive Psychology, 11, 295-314.

Pennington, B. F. (1997). Dimensions of executive functions in normal and abnormal development. In N. A. Krasnegor, G. R. Lyon, \& P. S. Goldman-Rakic (Eds.), Development of the prefrontal cortex (pp. 265-281). Baltimore: Paul H. Brookes Publishing Co., Inc.

Phillips, L. (1997). Do "frontal tests" measure executive function? Issues of assessment and evidence from fluency tests. In P. M. A. Rabbitt (Ed.), Methodology of Frontal and Executive Functions. Hove: LEA.

Pickering, S., \& Gathercole, S. (2001). Working Memory Test Battery for Children (WMTB-C). London: Psychological Corporation

Prabhakaran, V., Rypma, B., \& Gabrieli, J. D. E. (2001). Neural substrates of mathematical reasoning: A functional magnetic resonance imaging study of neocortical activation during performance of the necessary arithmetic operations test. Neuropsychology, 15(1), 115-127.

Quinn, J. G., \& McConnell, J. (1999). Manipulation of interference in the passive visual store. European Journal of Psychology, 11, 373-389.

Quinn, J. C., \& McConnell, J. (2000). Interference in visual working memory. Quarterly journal of Experimental Psychology, 53A, 53-67 
Riding. R., Grimley, M., Dahraei, H., \& Banner, G. (2003). Cognitive style, working memory and learning behavior and attainment in school subjects. British journal of Educational Psychology, 73, 149-169.

Rittle-Johnson, B. \& Siegler, R. S. (1998). The relationship between conceptual and procedural knowledge in learning mathematics: A review. In C. Donlan (Ed.), The Development of Mathematical Skills (pp. 75-110). East Sussex, UK: Psychology Press.

Ross, G. Tesman, J. Auld, P. A. M., \& Nass, R. (1992). Effects of subependymal and mild intraventricular lesions on visual attention and memory in preterm infants. Developmental Psychology, 28, 1067-1074

Rourke, B. P. (1993). Arithmetic disabilities. specific and otherwise: A neuropsychological perspective. Journal of Learning Disabilities, 26, 214-226

Rourke, B. P., \& Conway, J. A. (1997). Disabilities of arithmetic and mathematical reasoning: Perspectives from neurology and neuropsychology. Journal of Learning Disabilities, 30 $34-46$

Ruff, H. A., \& Rothbart, M. K. (1996). Attention in early development: Themes and variations. New York: Oxford University Press.

Russell, J., Jarrold, C., \& Henry, L. (1996). Working memory in children with autism and with moderate learning difficulties. Journal of Child Psychology and Psychiatry, 37. 673-686.

Rypma, B., Berger, J. S., \& D'Esposito, M. (2002). The influence of working memory demand and subject performance on prefrontal activity. Journal of Cognitive Neuroscience, 14 $721-731$.

Seitz. K. \& Schumann-Hengsteler, R. (2000). Mental multiplication and working memory European Journal of Cognitive Psychology, $12,552-570$

Seron, X. Pesenti, M., Noel, M., Deloche, G. \& Cornet, J. (1992). Images of numbers, or "When 98 is upper left and 6 sky blue." Cognition, 44, 159-196

Siegel, L. S., \& Ryan, E. B. (1989). The development of working memory in normally achieving and subtypes of learning disabled children. Child Development, 60, 973-980

Siegler, R. S. (1988). Strategy choice procedures and the development of multiplication skill. Journal of Experimental Psychology: General, 117, 258-275

Siegler, R. S. \& Shrager, J. (1984). Strategy choice in addition and subtraction: How do children know what to do? In C. Sophian (Ed.), Origins of Cognitive Skill. Hillside, NJ: Erlbaum Siegler, R. S. (1999). Strategic development. Trends in Cognitive Sciences, 3, 430-435.

Smidts, D. P., Jacobs, R. \& Anderson, V. (2004). The object classification test for children (OCTC): A measure of concept generation and mental flexibility in early childhood. Developmental Neuropsychology, 26, 385-401.

Sophian, C. (1996). Children's Numbers. Boulder, CO: Westview Press.

Stroop, J. R. (1935). Sudies of interference in serial verbal reactions. Journal of Experimental Psychology, 18, 643-662.

Swanson, H. L. (1993). Working memory in learning disability subgroups. Journal of Experimental Child Psychology, 56, 87-114

Swanson, H. L. (1999). Reading comprehension and working memory in learning-disabled readers: Is the phonological loop more important than the executive system? Journal of Experimental Child Psychology, 72, 1-31.

Swanson, H. L.. Ashbaker, M. H., \& Lee, C. (1996). Learning disabled readers working memory as a function of processing demands. Journal of Experimental Child Psychology, 61 $242-275$.

Swanson, H. L., Cooney, J. B., \& Brock, S. (1993). The influence of working memory and classification ability on children's word problem solution. Journal of Experimental Child Psychology, 55, 373-395.

Taylor. H. G.. Hack, M., Klein, N. K. \& Schatschneider, C. (1995). Achievement in children with birth weights less than 750 grams with normal cognitive abilities: Evidence for specific learning disabilities. Journal of Pediatric Psychology, 20, 703-719.

Taylor, H. C., Klein, N. K., Minich. N. M.. \& Hack, M. (2000). Middle-school-age outcomes in children with very low birthweight. Child Development, 71, 1495-1511.
Towse, J. N., \& Hitch, G. J. (1995). Is there a relationship between task demands and storage space in tests of working memory capacity? Quarterly journal of Experimental Psychology. $48 A .108-124$

Towse, J. N., Hitch, G. J. \& Hutton, U. (1998). A reevaluation of working memory capacity in children. Journal of Memory and Language, 39, 195-217

Tymms, P. (1999). Baseline Assessment and Monitoring in Primary Schools: Achievement. Attitudes, and Value-Added Indicators. London: David Fulton Publishers.

Wechsler, D. (1977). Wechsler Intelligence Scale for Children-Revised. Windsor: NFER-Nelson Wechsler, D. H. (1990). Wechsler Preschool and Primary Scale of Intelligence-Revised. Kent: The Psychological Corporation

Welsh, M. C., \& Pennington, B. F. (1988). Assessing frontal lobe functioning in children: Views from developmental psychology. Developmental Neuropsychology. 4(3), 199-230.

Welsh, M. C., Pennington, B. F., \& Groisser, D. B. (1991). A normative-developmental study of executive function: A window on prefrontal function in children. Developmental Neuropsychology, 7(2), 131-149

Wilson, K. M., \& Swanson, H. L. (2001). Are mathematics disabilities due to a domain-general or domain-specific working memory deficit? Journal of Learning Disabilities, 34, 237-248.

Woodcock. R. W. \& Johnson, M. B. (1989). Woodcock-Johnson Psycho-Educational BatteryRevised. Allen, TX: DLM Teaching Resources

Wynn, K. (1992). Addition and subtraction by human infants. Nature, 358 (6389), 749-750.

Zago, L., Pesenti, M., Mellet, E., Crivello, F., Mazoyer, B., \& Tzourio-Mazoyer, N. (2001). Neural correlates of simple and complex mental calculation. Neuroimage, 13(2), 314-327. 